\title{
SARS and occupational health in the air
}

\section{K Lim, D Koh}

\section{Educational efforts aimed at communicating the facts and dispelling the myths about SARS are required}

S evere acute respiratory syndrome (SARS) first surfaced in Guangdong, China in November 2002. It simmered there for three months, under a shroud of secrecy, before arriving in Hong Kong, Vietnam, Singapore, and Canada on modern jet planes. Thirty countries are now affected. As of 10 June, WHO has reported 8430 probable SARS cases and 789 deaths, giving a case fatality rate of $10.7 \%{ }^{1}$

The illness is caused by a novel coronavirus (SARS-CoV) measuring between 0.1 and 0.2 microns. ${ }^{23}$ Clinical features are those of atypical pneumonia, with the common presenting symptoms being fever greater than $38^{\circ} \mathrm{C}$ and a dry cough. ${ }^{4}$ Empirical treatment consists of corticosteroids, broad spectrum antiviral agents, and antibacterial cover. ${ }^{5}$ The primary mode of transmission is through droplets, as when an infected person sneezes or coughs. World Health Organisation (WHO) officials have acknowledged that air travellers "within two rows of an infected person could be in danger" ${ }^{6}$ However, the virus has also been found to survive for days in the environment, ${ }^{7}$ giving rise to the possibility of spread by contact with surfaces such as armrests and tray tables.

Coming close on the heels of international terrorism and the Iraq war, SARS has all but dashed the hopes of an early recovery for the ailing airline industry. As panic stricken travellers stay at home, anxious aircrew are clamouring for protection from occupational exposures.

In the first documented case of inflight, occupationally related transmission of the disease, a Singapore Airlines (SIA) flight attendant has been diagnosed with SARS after working on a 14 March flight between New York and Frankfurt, Germany, which had carried an infected doctor, his pregnant wife, and mother-in-law, all of whom it is now known, were incubating the SARS virus. The 32 year old Singapore doctor had in early March treated two SARS patients in Singapore. He subsequently attended a medical conference in New York but fell ill there with fever and symptoms suggestive of atypical pneumonia. He sought medical advice and was cleared by a New York physician to fly. However, Singapore's Ministry of Health got wind of it through a medical colleague he had spoken to over the phone just before boarding the flight, and contacted SIA and the health authorities in Germany to inform them of the situation.

When the plane landed in Frankfurt the doctor and his two asymptomatic travelling companions were admitted to hospital for treatment and observation. The remaining Singapore bound passengers were put on board another SIA aircraft and flown to Singapore the next day. Subsequently, the Singapore doctor's mother-in-law and wife also developed SARS in Frankfurt and were treated. Fortunately, all three recovered uneventfully. But the female flight attendant, who had worked in the rear section of the plane where the trio was seated, developed SARS after arriving in Singapore. The entire crew had to be quarantined, and the aircraft thoroughly disinfected.

In-flight, passenger to passenger transmission has also been implicated. When a cluster of 13 passengers became infected with SARS Co-V during Hong Kong to Beijing Air China Flight 112 on 15 March, ${ }^{8}$ a 73 year old passenger was believed to be the source. However, that was not the end of the matter, for subsequently, the Hong Kong authorities had to trace all passengers and crew who travelled on 21 March from Beijing to Hong Kong on Air China Flight 111, or from Hong Kong to Taipei on Cathay Pacific Flight 510, as four passengers from Taiwan who developed symptoms of SARS during their stay in Beijing (and who were believed to have contracted the disease while on board the 15 March Air China Flight 112), had returned to Taiwan on the two flights.

Needless to say, flight attendants have been on edge. The US Association of Flight Attendants has petitioned the Federal Aviation Administration to issue an emergency order requiring airlines to offer gloves and surgical masks to airline attendants, or at least allow them to bring their own. ' Some airlines flying Asian routes have on their own taken steps to issue masks to passengers and their crew and begun wiping down the interior of the plane with disinfectant. Some are issuing surgical gloves for flight attendants to handle trash from people who seem sick.

"The best sources of information are the WHO and US Center for Disease Control websites"

There has been rapid progress in the understanding of the nature of the disease, but many unanswered questions remain; for example: Are asymptomatic patients infectious? Are N-95 masks sufficiently protective? Is aircraft cabin air quality an issue? Until we know more, it would seem prudent to follow the standard recommended precautions based on the assumption of possible spread by droplet and contact. Hand washing, for instance, is perhaps the single most important personal hygiene measure. An excellent guideline on infection control guidance for airline personnel, including infection control guidelines for air flight cabin crew, aircraft cleaning crew, airport staff, and quarantine officers can be found at http://www.hc-sc.gc.ca/pphbdgspsp/sars-sras/prof_e.html. As the SARS situation changes very rapidly, the best sources of information are the WHO and US Center for Disease Control websites (http://www.who.int/csr/sars/ en/ and http://www.cdc.gov/ncidod/sars/). The WHO posts a daily situation update, while the CDC website has a fact sheet and frequently asked questions page, both of which are updated regularly.

There is no doubt that tightened SARS screening measures taken by airlines and airports have lessened the risk of catching SARS on board a plane. Airports on high alert are in fact beginning to look more like hospitals-as 24 hour frontline staff, armed with thermometers, masks, disinfectants, declaration forms, and health alert notices, take no chances. It was Singapore that first introduced walk-through infrared thermal scanners at Changi Airport for outbound travellers as well as inbound passengers from SARS affected countries. This technology, aimed at detecting individuals with fever, has since caught on in several airports in Asia.

No screening method, however, is foolproof. Illustrative of the pandemonium that can result from a single breach is the case of the 48 year old man who boarded a Lufthansa flight on 28 March and flew to Europe, where he crisscrossed the continent. He had flown on seven Lufthansa passenger jets in all, from Hong Kong to Munich, Barcelona, Frankfurt, London, Munich again, Frankfurt again, and then back to Hong Kong before entering a hospital. ${ }^{10}$ It was in Barcelona, on 31 March, where he 
began showing symptoms of SARS. On 10 April, the Hong Kong Department of Health issued a worldwide appeal for passengers and air crews from all seven flights to consult their doctors.

Earlier, on 5 April, Qantas airline staff had their turn to frantically contact 310 passengers of Flight QF 094 from Los Angeles to Melbourne because three children they shared the flight with were suspected of having SARS (which later turned out not to be the case). There have also been other false alarms, as when the American Airlines flight carrying 125 passengers from Tokyo was detained for more than two hours on the tarmac at San José, California.

In probable overreaction, Sudanese authorities on 26 April disallowed 72 Chinese nationals from disembarking at Khartoum's airport for fear that they might be infected with SARS. The Chinese passengers were forced to return on the same Gulf Air flight that brought them to Khartoum after other passengers were let out of the plane and into the country. ${ }^{11}$ On the other hand, Air India has had to suspend 45 pilots who refused to fly to destinations where SARS is prevalent, or with flight crew who had been in these countries within the past 10 days. ${ }^{12}$ The issue has since been resolved-it turned out that the pilots' actions were motivated by other non-SARS related grouses as well. ${ }^{13}$

The above instances, however, serve to emphasise the psychosocial dimensions of the SARS problem ${ }^{14}$ which, if not managed, could easily blow out of proportion. Aircrew are human and their fears of contagion, and of infecting family, friends, and colleagues (on top of security concerns relating to terrorist actions and rumours of layoffs) are real. Passengers have legitimate fears too, like sitting next to a SARS infected person. All too often, rumours outpace official information. Educational efforts aimed at communicating the facts and dispelling the myths about SARS, and the proactive steps to allay commonly perceived fears, backed by sensible and reassuring preventive measures, are therefore needed.

To the extent that on-board spread of the disease is a possibility that potentially endangers aircrew and passengers alike, SARS is an occupational and public health concern which the airline industry cannot ignore or simply wish away. The safety and wellbeing of aircrew and passengers must be accorded priority. At the same time, there is no need for the fear of SARS to be more contagious than the illness itself.

Occup Environ Med 2003;60:539-540

\section{Authors' affiliations}

M-K Lim, D Koh, Department of Community, Occupational and Family Medicine, Faculty of Medicine, National University of Singapore

Correspondence to: Professor D Koh, Department of Community, Occupational and Family Medicine, Faculty of Medicine, National University of Singapore; cofhead@nus.edu.sg

\section{REFERENCES}

1 World Health Organisation. Cumulative number of reported probable cases of severe acute respiratory syndrome (SARS). Available at: http://www.who.int/csr/sarscountry/ 2003_06_10/en/

2 Ksiazek TG, Erdman D, Goldsmith C, et al. A novel coronavirus associated with severe acute respiratory syndrome. N Engl J Med.
Available at: http://content.nejm.org/cgi/ reprint/NEJMoa030781v3.pdf.

3 Drosten C, Gunther S, Preiser W, et al. Identification of a novel coronavirus in patients with severe acute respiratory syndrome. N Engl J Med. Available at: http://content.nejm.org/cgi/reprint/ NEJMoa030747v2.pdf.

4 Hsu L-Y, Lee C-C, Green JA, et al. Severe acute respiratory syndrome (SARS) in Singapore: clinical features of index patient and initial contacts. Emerg Infect Dis [serial online] 2003 Jun [date cited];9. Available at: http://www.cdc.gov/ncidod/EID/vol9no6/ 03-0264.htm.

5 Chan-Yeung M, Yu WC. Outbreak of severe acute respiratory syndrome in Hong Kong Special Administrative Region: case report. BM 2003;326:850-2.

6 Koubek C, Loose C, Sottili C. Protecting yourself as SARS fears increase. Washington Post, 13 April 132003.

7 World Health Organisation. First data on stability and resistance of SARS coronavirus compiled by members of WHO laboratory network. Available at: http://www.who.int/ csr/sars/survival_2003_05_04/en/ index.html.

8 Anon. World's airports step up measures to fight SARS. International Herald Tribune, 29 March 2003

9 The Association of Flight Attendants. AFL-ClO press release. Flight attendants demand protection from SARS. Washington, DC, 3 April 2003.

10 CNN.com. Frequent flyer takes SARS on board. 13 April 2003.

11 AFP.Sudan rejects 72 Chinese passengers on SARS fears: airline. 26 April 2003.

12 Radio Australia Asia Pacific. Air India pilots suspended over SARS ban. Available at: http://www.abc.net.au/asiapacific/news/ GoAsiaPacificBNA_843103.htm.

13 Press Trust of India. Air India pilots call off stir. New Delhi, 2 May 2003. Available at: http://www.hindustantimes.com/news/ 181_244662,0008.htm.

14 Maunder R, Hunter J, Vincent L, et al. The immediate psychological and occupational impact of the 2003 SARS outbreak in a teaching hospital. www.cmaj.ca, 16 April 2003. 